\title{
POPULAR MEDIA AND CONSUMPTION
}

DOI: 10.17261/Pressacademia.2018.943

RJBM- V.5-ISS.3-2018(2)-p.191-201

Nese Mesutoglu Kirim

Bahçeşehir Üniversitesi, İletişim Fakültesi, Galata, Istanbul, Turkey.

nesenur@gmail.com, ORCID: 0000-0003-3332-2543

Date Received: April 16, $2018 \quad$ Date Accepted: August 30, 2018

To cite this document

Mesutoglu Kirim, N. (2018). Popular media and consumption. Research Journal of Business and Management (RJBM), V.5(3), p.191-201.

Permemant link to this document: http://doi.org/10.17261/Pressacademia.2018.943

Copyright: Published by PressAcademia and limited licenced re-use rights only.

\section{ABSTRACT}

Purpose- This study aims to explore emergence and the impact of capitalism in Turkish press. Until 1950s in Turkey newspaper bosses had been someone who had trained in journalism. This paper investigates how In the 1980s, the media organs which was shaped by tradition of journalist employers passed into professional employers who was not in media and then the artisanship came to end in the press and also analyse its effect on content.

Methodology- A face-to-face questionnaire was administered to reporters at Istanbul in 2018 and also through a literature review of articles on newspaper's mag pages, pressman experience and press owner experience, Pareto's treatment of the circulation of elites are discussed and the empirical approaches to measure the reader experience are examined. Adorno's culture industry theory is able to show how culture has assumed the form of a tool of domination.

Findings- Although there is a significant number of studies on the topic in the printed media literature, a commonly accepted scale measuring the reader experience has not been developed yet in the literature in Turkey. However, the literatüre and questionnaires highlight the dimensions and show the parallelism between ownership transition and transformation of cultural medium such as newspaper into the meta. As a result of that it is revealed that magazine news affects consumer behavior.

Conclusion- By the change of employers' magazine news became the most effective method to reduce the journalists to silence as a selfcensor mechanism. In this process, all the instruments of the culture industry were directed towards producing an apolitical, non-critical society. Mag pages of magazines and newspapers in Turkey; served to present and promote consumer culture.

Keywords: Artisanship, culture industry, magazine, elite.

JEL Codes: L82, J50, Z10

\section{MAGAZIN SAYFALARINDA TÜKETIM ETKISI}

\section{ÖZET}

Amaç- Bu çalışmanın amacı kültür endüstrisinin okurun günlük faaliyetlerine magazin haberleriyle nüfuz ederek onu nasıl yönlendirdiğini ve tüketim sarmalına çektiğini ortaya koymaktır. Kapitalizmin gelişme sürecinde Türk basınındaki istihdam yapısının değişimini ve bunun içerik üretimine etkisi incelenmektedir. Makalede, yazılı basının kültür aracından metaya dönüş sürecinin başladığı 80'li yıllardan itibaren gazeteci işverenler geleneğiyle biçimlenen medya organlarının basın dışı işverenlerin eline geçişi ve bunun sonucunda zanaat döneminin sona ermesiyle yaşanan dönüşüm ve içeriğe magazin sayfalarındaki artış olarak yansıması masaya yatırılmaktadır.

Yöntem- Bu makalede magazin haberlerinin içeriğine ilişkin olarak; gazete ekleri ve magazin dergileri yazı işleri çalışanlarıyla gerçekleştirilen derinlemesine görüşme yöntemiyle sektörel analizi destekleyecek bulgular elde edilmiştir. Pareto'nun seçkin dolaşımı teorisi tartışılmakta ve okuyucu deneyimini ölçmek için ampirik yaklaşımlar incelenmektedir. Adorno'nun kültür endüstrisi teorisi, kültürün tahakküm aracı rolünü nasıl üstlendiğini göstermeye yardımcı olmaktadır.

Bulgular- Yazılı basın literatürü üzerine çok sayıda çalışma olmasına rağmen, Türkiye'de yazılı basının okurun davranış değişikliğine etkisini ölçen yaygın kabul görmüş bir ölçek henüz geliştirilmemiştir. Bununla birlikte, derinlemesine görüşmeler ve mevcut literatür taraması sayesinde gazetelerin sahiplik yapısındaki değişimle gazete gibi bir kültür aracının metaya dönüşmesindeki paralelliğe dikkat çekilmektedir. Bunun sonucunda magazin haberlerinin tüketici davranışını etkilediği ortaya konulmaktadır.

Sonuç- Basında sahiplik yapısı değişirken Türk gazetecilerini susturma yöntemi olarak kullanılan en etkili yöntem, bir otosansür mekanizması olarak magazin haberleri oldu. Bu süreçte kültür endüstrisinin bütün enstrümanları apolitik, eleştirellikten uzak bir toplum üretmeye yöneldi. Türkiye'de dergi ve gazetelerin magazin sayfaları; tüketim kültürüne ilişkin içerik oluştururken, tüketime yönelik yaşam tarzlarını teşvik eden ve tanıtımını yapan mecralara dönüştü.

Anahtar Kelimeler: Zanaat, kültür endüstrisi, magazin, seçkin.

JEL Kodları: L82, J50, Z10 


\section{GiRiş}

Türkiye'de 1980 sonrası siyasi ve ekonomik yeniden yapılanma dönemine girildiğinde; temelleri tamamen ekonomiye dayanan medya-sermaye ve iktidar üçgeni gündeme taşındı. Bu üçlü yapının arka planında ise doğal olarak, basında ticarileşme ve holdingleşme olgusu yatıyordu. Medya alanındaki sermayenin büyümesi hedeflenirken, medya gerek finansal gerekse teknolojik açıdan desteklenerek bir sektör haline getirildi.

Bu dönemde, "Medya, değişik sermaye gruplarının kitle iletişim alanına girmesiyle hızlı bir değişime uğradı. Ticari radyo ve televizyon kanalları yaygınlaştı. Yazılı basın ise 1980 öncesine göre çeşit, baskı ve sayfa kalitesi açısından değişim geçirmesiyle bir sanayi sektörüne dönüştü" (BALI, 1999). Bunun sonucunda o güne kadar bir kültür aracı olarak toplumda yer bulan yazılı basın, popüler kültürün bir tüketim unsuru haline geldi.

Bu süreç medyanın magazinleşmesi ve magazin medyasının bu yeni dönemde egemen bir görünüm sergilemesiyle başladı. Bunun ardında yatan temel nedenlerden biri, 12 Eylül 1980 müdahalesi sonrasında toplumun apolitikleştirme sürecine girmiş olmasıydı. Popülerleştirilmiş veya magazinleştirilmiş haber bültenleri, bağımlılık yaratan etkisiyle insanı bir hayal dünyasında ve toplumsal iktidar ilişkilerinin dışında tutmayı hedefliyordu.

Türk Dil Kurumuna göre magazin; halkın çoğunluğunu ilgilendirecek, çeşitli konulardan söz eden, bol resimli yayındır. Genellikle sanat, eğlence ve spor dünyasında tanınmış kişilerle ilgili haber ve yorumdur. Magazin haberciliğinde toplumu ilgilendiren olayların ikincil öğeleri ön plana çıkar. Magazinsel söylem, olay örgüsünü parçalar ve gerçekliğinden koparır. Ortalama bireyler için olan, tüketilmesi kolay, basit ve yüzeysel hale getirir. Böylece okuyucunun kolaylıkla tüketebileceği bir içerik oluşturulmaktadır.

Medyanın yeniden şekillendiği ve siyasi haberlerden uzaklaşıldığı bu dönemde magazin haberleri hem gazete patronları hem de çalışanların tercihi oldu. Gündelik bilgiye dayanan bu haberlere ulaşmak kadar bu haberleri hazırlamak da kolay ve hızlı bir çözüm sunuyordu. Bu tarz haberlerde büyük resimler ve kısa yazılarla ilgi çekmeye çalışılıyordu. Bunun sonucunda teknik bilgi gerektirmeyen bu gazetecilik dilinin baskın olarak yer edinmesiyle medya profesyonellerinin profilinde yaşanan değişim arasında -neden sonuç ilişkisi olarak da değerlendirebileceğimiz- bir paralellik yaşandı.

Kültür Endüstrisi'nin araçlarından biri olan magazin basını, kapitalizmin etkisiyle ortaya çıkan bir kültürel oluşum olarak gündemdeki yerini aldı. Bu dönem "Endüstriyel tekniklerle üretilen ve çok geniş kitlelere yayılan, karşı konulması güç davranış, mitos ya da temsili olguların tümü" (ÖZKÖK, 1982) diyebileceğimiz kültür endüstrisi, teknolojik yatırım ve gelişmelerle, kitle iletişiminin olduğu modern kitle toplumunun tipik kültürü olarak Türkiye'de nüfuz etmeye başladı. Frankfurt Okulu düşünürlerinden Adorno'nun dediği gibi kültür endüstrisi, tekelci kapitalizmin bir sonucu olarak kültürel biçimlerin metalaşması olarak kullandı. Kapitalizm, Türkiye'de de kültür endüstrisi aracılığıyla insanın yaşam ve üretim biçimleri üzerindeki etkisini her gün daha da artırarak gelişim gösterdi. Kültür endüstrisi hem toplumun tüm öğelerini hem de insanın düşünce ve duygularını belirlerken haberin yaratılma biçimlerine de nüfuz etti. Bu çalışmanın amacı kültür endüstrisinin insanın günlük faaliyetlerine magazin haberleriyle nüfuz ederek bireyleri nasıl yönlendirdiğini ve tüketim sarmalına çektiğini ortaya koymaktır.

Bu makalede magazin haberlerinin içeriğine ilişkin olarak; gazete ekleri ve magazin dergileri yazı işleri çalışanlarıyla gerçekleştirilen derinlemesine görüşme yöntemiyle sektörel analizi destekleyecek bulgular elde edilmiştir. Bu çalışma bir otosansür aracı olan magazin gazeteciliğinin gelişimine odaklanmış, bir kültür endüstrisi ürünü olarak magazin basınının gelişimini öne çıkarmıştır. Bu süreçte basında istihdam modellerindeki değişim vurgulanırken gazetelerinin sahiplik yapısındaki gelişimle istihdam yapısında 'zanaat' benzeri (artisan like) iş bölümü yerine fabrika benzeri' (factory-like) üretim ilişkileri incelenmiş, gazete gibi bir kültür aracının metaya dönüşmesindeki paralelliğe dikkat çekilmiştir.

\section{LITERATÜR ÖZETi}

Osmanlı-Türk basın tarihinde 1948 'e kadar gazete patronları hep gazetecilikten yetişmiş kimselerdi. Genelde patron gazetenin başyazarı olurdu. Tanzimat'ta, İstibdat'ta, Meşrutiyet'te ve Cumhuriyet'in ilk 25 yılında durum aynıydı. Cumhuriyet'in başlarından II. Dünya Savaşı sonlarına kadar patron-gazeteci geleneği sürdü. Yunus Nadi (Cumhuriyet), Necmettin Sadak (Akşam), Zekeriya ve Sabiha Sertel, Halil Lütfü Dördüncü (Tan), Ahmet Emin Yalman (Vatan), Ali Naci Karacan (Milliyet), Cihat Babacan ve Ziyat Ebüzziya (Tasvir), Hakkı Tarık ve Asım Us (Vakit), Cemalettin Saracoğlu (Yeni Sabah), Selim Ragıp Emeç (Son Posta), Etem İzzet Benice (Son Telgraf), Faruk Gürtunca (Hergün), Şevket Bilgin (Yeni Asır), Sedat Simavi (Hürriyet), Falih Rıfkı Atay (Dünya) patron gazetecilerin son örnekleri oldu. Türk basını kitlesel gazeteciliğin ortaya çıkmaya başladığı 1950'li yıllarda karakteristik özellikler kazandı. Politik haberlerin ve fikir tartışmalarının yanı sıra edebi türler de gazetelerde yer alıyordu. Bu dönemde yayınlanan gazetelerde haberler edebiyatçıların elinden çıkmaktaydı. Genellikle edip yazarlar, yani gazetede yazan edebiyatçılar istihdam ediliyordu. (ADAKLI, 108) Önde gelen yazarlar, gazete ya da dergilerde düzenli yazılar yazıyordu. Objektif normlardan uzak bu süreçte 'fikir gazeteciliği' ön plandaydı. Gazeteedebiyat ilişkisi açısından Faik Baysal "1945-1955 arası edebiyatın altın yıllarıydı. Gazeteler edebiyat ekleri yayımlıyordu," diyor (BAYSAL, 2003). Bu yıllarda; 
a) Sait Faik'in hikâyeleştirdiği adliye röportajları 6-31 Mayıs 1942 tarihleri arasında Haber gazetesinde yayınlandı. (ABASIYANIK, 1965)

b) Orhan Kemal'in, Nazım Hikmet'in telkinleriyle yazdığı ilk düzyazısı 'Balık' başlıklı hikâyesi ile onu takip eden ilk hikâyeleri Yeni Edebiyat Gazetesi'nde yayınlandı.

c) Attila İlhan'ın ilk şiiri 'Balıkçı Türküsü’ yine Yeni Edebiyat Gazetesi'nde çıktı.

ç) Akşam gazetesinde 1946 ' da Vâ- Nû ve Refik Halit Karay yazmaktaydı.

d) Sermet Sami Uysal'ın 'Aşk Her Şeyin Üstünde' adlı romanı 1954'te Cumhuriyet'te tefrika edildi.

e) 11 Mayıs 1956 ile 16 Haziran 1957 tarihleri arasında Yahya Kemal'in her hafta Hürriyet'te en az bir şiiri yayınlandı. Bu şiirlerin toplam sayısının 79 olduğu bilinmektedir. (ÇIKLA, 2008)

f) 1950 'li yıllarda “Gazete köşelerini dolduran yazarların birçoğunun edebiyatçı olması dikkat çekicidir. O dönemde Necip Fazıl, Peyami Safa, Hüseyin Cahit, Haldun Taner, Falih Rıfkı Atay, Oktay Akbal ve daha birçok şair ve yazar gazetelerde yazılar yayınlar. Bunlar gerek dönemin politikasını gerek edebî hayatını ve sanatını eleştirerek yönlendiren, renklendiren ve ayakta tutan kişilerdir." (GÜLENDAM, 2004)

g) Ahmet Hamdi Tanpınar'ın Huzur'u 1948'de Cumhuriyet gazetesinde, 'Sahnenin Dışındakiler'i de 1950'de Yeni İstanbul gazetesinde tefrika edildi. (AKÜN, 2002) Yine Tanpınar 1938'den itibaren 1961'e kadar bazen sık sık bazen de aralıklarla Cumhuriyet'te yazdığı bilinmektedir. (ÇIKLA, 2009) 1960'lara kadar şair ve yazarların gazetelerde eserlerini yayınlanıyor, tefrika ediliyordu.

Gazetenin tamamında kullanılan dil ve üslup günümüzdekinden oldukça farklıydı. Bu tür bir üslup objektif habercilik normlarından uzaktı. (ADAKLI, 2006) Nitekim basının endüstrileşme sürecinin hızlandığı 60'lı yılların sonunda Cumhuriyet Gazetesi Genel Yayın Yönetmeni Ecvet Güresin, Oktay Akbal'ın gazetede edebi türde yazmak istemesine karşılık şunları söylemiştir: "Sen edebiyatçısın, belki edip yazarların sonuncususun, yani gazetede yazanların. Şimdi okur değişti. Edebiyatçıların modası geçti. Şimdi toplumsal, siyasal ağırıklı yazılar aranıyor." (AKBAL, 1992)

1948-1950 yıllarında iş adamlarının basınla ilgilenmeye başlamasıyla muhabir ve yazar profili de değişmeye ve Babıali'de yeni bir dönemin sinyalleri verilmeye başladı. Gazete sahiplerinin gazetecilikten geldiği, çalışanların edebiyatçılardan oluştuğu bu dönemde, kapitalist koşullarda günümüzün profesyonelleşme ve uzmanlaşmaya dayalı iş bölümü değil, 'zanaat' benzeri (artisan like) bir iş bölümü hakimdi. (ADAKLI, 2006) Burjuvaziye mensup gazete sahipleri, entelektüel formasyonu güçlü fikir adamları olarak gazetenin içeriğinde söz sahibiydi. Sahiplik yapısı fikir düzeyinde buluşan birkaç ortağın koyduğu sermayeye dayanıyordu. Medya sektörü, 1980 'lere kadar gazetecilikten yetişmiş aile işletmelerinin hâkimiyetinde kaldı. Bu tarihten sonra ise endüstrileşme ve profesyonelleşme önem kazandı.

Basın sektöründeki sahiplik yapısındaki değişimin ilk elden tanığı olarak 1969 yılında foto muhabiri olarak göreve başlayan Garbis Özatay bu konuda şöyle konuşmaktadır: "Eski yıllarda imkânsızlıklar içinde çalışıyorduk. Yine de her aşamada gazeteciliğin kalitesi, saygınlığı vardı. Üzülerek söylüyorum ki bugün bu saygınlık maalesef kalmadı. Bunun da kaybolmasının en büyük nedeni patronlardır diye düşünüyorum. Çünkü insana yatırım yapmaktan kaçındılar. Eski gazete sahipleri, sadece gazeteyle ilgilenirdi ama daha sonra holdingleşmeyle gazeteciliğin yanında girdikleri sektörlerin sorumluluklarını da alarak gazetecilik mesleğini sıradanlaştırdılar." (KILIÇ, 2015)

Birinci kuşak basın sahipleri genellikle basın dışında faaliyet göstermiyor, burjuva ailelere mensup entelektüellerden oluşuyordu. Birden fazla yabancı dil biliyor, gençliklerinden itibaren o dönem üst zümreye has bir nitelik olan yurt dışı deneyimine sahip bulunuyordu. Çocukları Batılı tarz eğitim veren okullara gitmiş, yabancı dil eğitimi almış, babaları gibi basın dışında bir faaliyet alanında yer almamıştı. Gazeteci babalarının izinden gitmek istemeyen, gazetecilik aşkı duymayan ikinci ve üçüncü nesil gazete sahipleri sektörün ruhunu değiştirmeye başladı. Basın sahiplerinin kuşaklar arasındaki değişimi, aile yapısı ve mesleki eğitim formasyonları konusundaki farklılaşmayla dikkat çekti. Yeni medya sahipleri gazeteciliği yaşam biçimi olarak gören bu kuşaklardan çok farklıydı. 1980'lerden itibaren basın dışı sektörlerde yatırım yaptılar ve çocuklarını şirket yönetimine hazırladılar. Böylece Türkiye’ye özgü dinamiklerle yeni bir kapitalist medya organizasyonu ortaya çıktı. Fikir gazeteciliğinden kitlesel gazetecilik dönemine geçerken, Türkiye'de basının endüstrileşme süreci başladı. 60'lardan itibaren tohumları atılan 'fabrika benzeri' (factory-like) üretim ilişkileri oluştu. (KILIÇ, 2015)

Böylelikle cumhuriyet döneminde başlayan 'gazeteci işveren' geleneği sona ererken medya organları basın dışı işverenlerin eline geçti. Basından gelen işverenler gazetecilik dışı faaliyetlerle birleşti. 1979'da gazetecilikten gelmeyen ilk patron Aydın Doğan'ın Milliyet gazetesini satın almasıyla başlayan ve 1988 'de Asil Nadir'in Türkiye'de bazı basın ve yayım kuruluşlarını almasıyla ivme kazanan basın dışı sermayenin Türk basınında yer alması ile ilgili oluşum ve aile tipi basın işletmesinden, finans-kapitali dışarıdan sağlanan basın kuruluşlarına geçiş modeli, döneme damgasını vuran en önemli örneklerden biri oldu. (ÖZGEN, 2008) Aydın Doğan'ın 1994 yılında Hürriyet Holding'in çoğunluk hisselerini Simavi ailesinden satın alması bir devrin sona erdiğinin işaretiydi. Gülseren Adaklı'nın Türkiye'de Medya Endüstrisi isimli kitabında belirttiği gibi Türkiye'de 
'fikir gazeteciliği' olarak bilinen basın faaliyetinden farklı olarak geniş kitleleri ortak duyu zemininde birleştiren 'yığın gazeteciliği'nin öncülüğünü bu gazeteler yaptı. "Modern baskı teknikleri, görsel malzemelerin yoğunluğu, milliyetçi/şoven çerçevede kurulan sansasyonel üslupları, yazı ve röportaj dizileri, advertorial sayfaların yanı sıra ilan ve reklam gibi finans olanaklarından azami oranda yararlanma konusunda da belirgin bir fark dikkat çekiyordu." (ADAKLI, 2006)

Sonuçta gazeteciliğin zanaat dönemini kapandı. Sanayileşme dönemini başladı. Bu dönem Türk basını yapısal olduğu kadar teknolojik bir değişim de yaşıyordu. Temel amaç kamuoyunu bilgilendirmek değil, sanayinin ve piyasanın temel ilkesi olan arz-talep mekanizmasına uyarak daha fazla kâr etmek oldu. Bu değişim basın kavramı yerine kullanılan 'medya' kavramında sembolik olarak anlamını buldu. Hükümetle olan ilişkiler artarak devam etti. Farklı gazeteleri bünyesinde toplayan holdinglerle tekelci eğilim güç kazandı. Ekonomik olarak dev teknolojik yatırımlar yapılan Türk medyası, ülkede yaşanan iktidar ilişkilerinin, yapısal değişimlerin, çıkar çatışmalarının, sınıfsal ilişki ve çelişkilerin, tarihsel kırılma noktalarının birebir yansıdığı bir alan oldu. Geleneksel basın semti Cağaloğlu’ndan kent dışındaki ikitelli'ye taşınma ile ticari radyo ve televizyonların kuruluşu, basın döneminden medya çağına geçişin kilometre taşı olarak kabul edildi. Bu taşınma sürecini Cumhuriyet gazetesi yazarı Şükran Soner (Bianet.org, 2008), “Gazetecilik, yaşamdan beslenen bir meslek. İkitelli'ye taşınma, gazetenin öneminin düşürülmesi, gazeteyi ayakta tutan değerlerin piyasa değerlerine dönüşmesidir," sözleriyle yorumladı. 1990 yılında ileri teknoloji ürünü donanımıyla, gösterişli biçimde İkitelli'ye ilk taşınan Bilgin Grubu (Medigrup), Sabah dışında kapasite kullanımını artıran Bugün, Yeni Yüzyıl, Fotomaç, Sabah Yıldızı gibi başka gazetelerle birlikte birçok dergi yayımladı. 1992 yılında temeli atılan Doğan Medya Center, bir yıl sonra hizmete açıldı ve Milliyet yeni plazaya taşındı. İstanbul basınının 90'ı yılların başında geleneksel mekânı Babıali'den İkitelli'ye taşınmasının sembolü olarak nitelenebilecek Hürriyet Medya Towers (HMT), 1993 yılında taşındı. Böylece 1990'lara kadar yaklaşık 160 sene devam eden Babıali geçmişi sona erdi.

Babıali ve gazeteci patron devri yerini medya plazalarına ve iş adamlarına bıraktı. 1980 sonrası Turgut Özal’ın “iki buçuk gazete yeter" sözleriyle yaklaşımını özetlediği bu dönemde, pek çok medya patronu farklı sektörlerde de güç sahibi oldu. Büyük sermaye dışındaki küçük gruplar için piyasa engelleri yüksek düzeyde rekabet yarattı. Nitekim 24 Ocak 1980'de alınan kararlarla devlet gazete kâğıdına verdiği sübvansiyonları kaldırılmasıyla sermayenin gelişmesi ve özel ilanların artmasıyla basının devlete bağımlılığı azalırken, kâğıt maliyetini karşılayamayan ve reklam alamayan dar bütçeli yayınlar piyasadan silindi. Kendi bankasından aldığı krediyle kendini ihya eden patron tipi, kendi medyasıyla gerçeklerin üzerini örtme çabasına girişti. 1990'lar genel ekonomide istikrarsızlık dönemleriyle anılırken, medya sektörüne yatırım yapan gruplar devletten sağladıkları gümrük indirimleri, teşvik ve ucuz kredilerle hızla güçlendi. (GÜR, 1983)

80 'li yıllar, medya endüstrisinin stratejik sektörler arasına yerleştiği bir dönem oldu. Medyaya yatırım artarken liberal politikalarla yapısal dönüşüm gerçekleşti. Genç, kentli, iyi eğitimli ve yüksek gelir düzeyine sahip Beyaz Türkler, korunaklı sitelere yerleşti. İyi yemek, puro ve şaraptan anlamak, statü simgesine dönüştü. İmaj çalışması sadece sahne sanatçıları değil, iş adamları için de önem kazandı. Rıfat Bali'ye (BALi, 2002) göre 80 sonrası gazete ve dergilerine medya-iş dünyasısiyasi iktidar sacayağında yer alan muktedirlerin dayattığı seçkinci bir ideoloji damga vurdu. Bu dönüşümün en önemli paydaları arasında 'yeni elitler' (BALI, 2002) ve bunlar içinde özel bir alt grup olarak 'medya elitleri' yer alıyordu. Medya yöneticileri güç odağı olduklarını ifşa edercesine gündemde yer alarak hükümetle iyi ilişkiler kurdu. 'Yeni Türk İnsanı' projesine uygun seçilen köşe yazarları, bu dönemin yeni aristokratları oldu. Köyden kente yoğun göç yaşanan bir ülkede kent yaşamı rehberi şeklinde burjuva sınıfı yaşam tarzına özendiren ve hatta öğreten yaşam tarzı yazıları günümüze kadar devam etti.

Bu yeni hayatı sunan gazeteciler ve tabii medya sahipleri, sınıf ilişkilerinden soyutlanarak 'elitler/seçkinler' olarak boy gösterdi. Innsanlık tarihini, seçkinlerin durmadan devam eden yer değiştirme tarihi olarak gören Pareto, 'Seçkinlerin Dolaşımı' teorisinde toplumsal sınıflar arasında geçiş olabileceğini, bazı bireylerin aşağı tabakadan olmakla birlikte bir üst tabakaya geçebileceğini de ileri sürmüştür. Bu döngüye göre zaman içinde ister istemez mevcut seçkinler yerlerini diğerlerine bırakmak zorunda kalır. Magazin basınının can damarı olan zümreyi anlatan 'seçkin' kelimesinin Kıta Avrupası'nda siyasi literatürde yaygın kullanımı 19'cu yüzyıl sonlarında, İngiltere ve Amerika'da ise 1930'larda başlar. Pareto, toplumun seçkinler ve seçkin olmayanlar olarak iki ana katmandan oluştuğunu ileri sürer (BOTTOMORE, 1990). Seçkinleri de yönetici olanlar ve olmayanlar şeklinde ikiye ayırır. " (BOTTOMORE, 1990)

Bottomore'a göre seçkin kavramı aslen toplumsal sınıf kavramına karşı kurgulanmıştır. Seçkin'i tanımlarken bu kavramlaştırmada esas alınan kişi ya da kümelerin toplumsal sınıf kökenleri değil statüleri, profesyonel konumları olmaktadır. Bottomore seçkinler deyimini "Her nedenle olursa olsun genellikle bir toplumda statüsü yüksek olan, işlevsel, esas olarak profesyonel kümeler" için kullanıldığını belirtmektedir (BOTTOMORE, 1990). Bu bağlamda seçkin kuramcıları Weber'in statü kavramlaştırmasına bel bağlar (WEBER, 1968). Örneğin György Lukacs, Pareto'nun seçkinler kavramının yerini Weber'de karizma kavramının aldığını öne sürmektedir. Yığınlar karar veremez, yönetemez ama seçkinler yapabilir. Seçkin kuramları, Lukacs'ın bir yönüyle işaret ettiği gibi bir yönetim aracı işlevi de görmektedir. Bu kuramların varsayımları sadece kuramcılar tarafından değil, bizzat kendisini ‘seçkin' olarak gören ve "Bir toplumun kültürüyle dolaysız ilgisi" bulunan kesimler olan gazeteciler ya da köşe yazarları tarafından bugün de kullanılmaktadır (WEBER, 1968) . 
Pierre Bourdieu ise seçkin kuramlarının genel olarak sınıf ve mülkiyet kategorilerine karşı kurdukları konumu sarsan eleştirilerde bulunuyor. Ekonomik sermayenin yanı sıra kültürel, toplumsal, sembolik, eğitim gibi sermaye türlerini çalışmasına dahil ediyor. Böylece köşe yazarı, yöneticiler gibi medya seçkinlerini tartışmaya sunan Pierre Bourdieu "Belirli bir sınıfın refahının bileşenleri" şeklinde açıklamaktadır. "Bourdieu, sermaye kavramını geleneksel ya da ticari anlamdaki sermayenin ötesine taşıyarak onu para biçiminde olmayan sermayeleri de kapsayacak şekilde genişletir. Özellikle sembolik, toplumsal ve kültürel sermaye. Sembolik sermaye saygın kurumların birliğine yaslanan ödüller verir. Böylece Oxbridge sembolik sermayeden yararlanır. Oxford ve Cambridge sözcüklerinden yapılmış bileşik sözcük olan Oxbridge, bu isimleri taşıyan ve burjuva sınıfına mensup olanların devam edebildiği seçkin üniversiteleri anlatmak için kullanılır. Bu sözcüğün karşıtı red-brick, İngiltere'de II. Dünya Savaşı sonrasında hükümet fonlarıyla, endüstri bölgelerinde yaşayan işçi çocuklarının teknik eğitimine yönelik olarak kurulmuş küçük üniversiteler için kullanılmaktadır. "Toplumsal sermaye, temas şebekelerine ve değiş-tokuş edebileceğimiz başka işlere sahip olmak suretiyle kazanılan avantajlardan meydana gelir. Kültürel sermaye ise özellikle ekonomik gerekliliklerin baskısından sıyrılmış boş zamana ilişkin yaşam tarzıyla rezonans içindeki belirli kültürel mallara sahip olmanın getirdiği avantajlardan oluşur. Diğer sermaye türleri ise dilsel ya da eğitimsel sermaye gibi türler olarak ayrılabilir. İnsanlar, bu sermaye türlerine sahip oluşlarına göre ayrılır, bunlara göre toplumsal nüfuzları ve iktidarları çeşitlenir. Insanlar, büyük ölçüde farkında olmaksızın kendilerine parasal ya da parasal olmayan karlar getiren bu tür sermayelere yatırım yaparlar." (SAYER, 1998) Bourdieu'nün bu yaklaşımına göre belirli bir eğitim sermayesine sahip olan medya profesyonelleri belirli bir yaşam tarzının hâkim olduğu toplumsal ilişkiler şebekesine girebiliyordu. (ADAKLI, 2006)

Fakat tarihteki en büyük değişmeler, Pareto'nun seçkinler dolaşımı olarak tanımladığı, bir elit grubun yerini başka bir elit grup aldığı zaman meydana gelir. Holdingleşme sürecinde el değiştiren Türk basınında ise güçlü sermayeleri olan yeni sahipler farklı sınıf kökenlerine mensup olsalar da yeni 'seçkin'leri oluşturdu. Gerek Türkiye'nin gerek dünyanın seçkin üniversitelerinden mezun olarak sembolik sermayeye sahip olan bu zümre, tüketim alışkanlıklarında da bu statülerini perçinleyecek seçimlerden yana kullandı. Bu tercihlerle kendi sahip oldukları Türkiye seçkinlerine özel Alem, Şamdan, Hello gibi dergilerde boy gösteren çocukları yönetim kadrolarında yer alırken, aynı zamanda da şov dünyasından isimlerle magazin basınının sayfalarını paylaştı.

Adnan Menderes-Celal Bayar ikilisinin Demokrat Parti'sinin siyasi felsefesi olsa da "Türkiye'yi küçük Amerika yapma" sözü adeta gerçek oldu. Türk medya sektörünün son 20 yıllık tarihi de kapitalist sınıfı oluşturan kesimlerin kavgalarının tarihine sahne olurken, öncelikli hedefleri farklı olan sermaye grupları bu süreçte magazin paravanı arkasında basın özgürlüğü ve etiğinin zedelenmesine kayıtsız kaldı. Serbest piyasa ekonomisinin hâkimiyetiyle birlikte tüketim, insanların kimliklerini belirleyen en önemli unsur haline geldi. Ürünlerdeki çeşitlenme medyada magazin haberleri aracılığıyla halka pazarlanmaya başladı. Kültürün tahakküm aracı rolünü nasıl üstlendiğini göstermeye yardımcı olan ve makalemizde sıkça referans verdiğimiz Adorno'nun kültür endüstrisi teorisinin de dikkat çektiği gibi kültür endüstrisinde üretim ve tüketim yapan tüm mekanizmalar egemen sınıfın çıkarlarını gözetirken, kültür endüstrisinin tüm ürünleri birbirine benzetilmiş, standart bir yapıya sahip oldu.

\section{VERI VE YÖNTEM}

Haberin magazinleşmesi halka dönük gazetecilik yapmak adı altında öncelikle Avrupa daha sonra Amerika'da yaygınlaşmıştır. Halka dönük gazetecilik birincisi, ilk anda dikkat çekebilecek konuları incelemek, ikincisi ucuza satmak olmak üzere iki temel unsura dayanıyordu. Bu haber anlayışıyla amaç toplumun ilgisini, ulaşmak istediği yaşam standardına sahip olan zengin tabakaya ve ünlü ve seçkinlerin hayatına yönlendirmekti. Batı'da (HALLIN, 2005) 19'ncu yüzyıldan itibaren günlük gazeteler, gazeteciliğin atası olarak bilinen metelik gazetelerinin (penny papers) ucuz fiyatı, tarafsızlık etiğiyle tanımlayarak magazin konularına ağırlık veren ve kitlesel tüketime yönelik ürünlere dönüşmesi Türkiye'de 20 'nci yüzyılda tezahür etti.

Bu makalede, 80'lerin mirası olan magazin basınının tüketimi özendirme ve artırmadaki rolü üzerine gazetelerin magazin sayfalarında muhabir, editör ve yönetici olarak çalışan otuza yakın basın mensubuyla yapılan görüşmelerden yararlanılmaktadır. Araştırmada derinlemesine görüşme yöntemi kullanılmıştır. Magazin haberlerinin içeriğine ilişkin olarak; gazete ekleri ve magazin dergileri yazı işleri çalışanlarıyla gerçekleştirilen derinlemesine görüşme yöntemiyle sektörel analizi destekleyecek bulgular elde edilmiştir. Basın sektöründe en popüler departmanlarından biri olan magazin bölümlerinde çalışanlar sektörel ve hatta ulusal tanınırlığa sahip oldukları için isimlerini vermemeyi tercih etmişlerdir. Sadece isimlerini kullanmamıza izin verenler, referans olarak gösterilmiştir.

Yukarıda da belirttiğimiz gibi Türk toplumu 1980'den bu yana hızlı bir dönüşüm geçirdi. Gündelik yaşamla beraber gazetelerin magazin sayfalarıyla renklendi. Bu dönem, basının medyaya dönüşme süreci olarak ifade edildi. Dönemin temel özelliklerinden biri 12 Eylül Dönemi'nde, basının ve halkın depolitizasyon sürecine girmesinin ve sansürün etkisiyle başlayan magazin içerikli yayın politikasının devam etmesi oldu. 12 Eylül döneminde gazeteler, üzerlerindeki baskı nedeniyle 'apolitik' bir tavır benimsemek zorunda kalırken, yazılı basının asıl görevi olan haber verme, bilgilendirme, toplumsal muhalefeti ifade etmek işlevinden uzaklaşarak magazinleşme eğilimine girdi. 
1950'lerde basın özgürlüklerini savunmayı ilke edinmiş, siyaseti her sütuna taşımış olan basın, 1970'lerde sivillerin ve davet ettikleri askerlerin çözüm getirmedeki başarısızlıkları sebebiyle politikayı suçlayarak toplumun bütün sıkıntılarının politikadan geldiğini ileri sürdü. Artık ilkelerden çok politikacıların kişilikleri eleştirilerek otosansürle gelen boşluk dolduruluyordu. (KOLOĞLU, 2013) Apolitizm meziyet gibi sunulmaya başlamıs, haberler yanlı ve yorumlu verilir olmuştu. Orhan Koloğlu bu dönemi "Gazeteciler Cemiyeti Başkanının deyimiyle gazeteciler kafalarını kuma sokup yaşamayı tercih ediyordu" diye anlatıyordu. Bu dönemde Gırgır ve Fırt adlı iki mizah dergisi, siyasi mizahla 400 ila 500 bin arası değişen tirajlara ulaştı. Terör ve anarşinin tırmanmayı sürdürdüğü bu dönemde gazetelerin içeriğini politikacıların seks skandalları, iki ünlü homoseksüel şarkıcının kıskançlık çekişmeleri ve Amerikan dizisi Dallas'a dair magazin haberleri oluşturuyordu. (KOLOĞLU, 2013)

1993 yılına gelindiğinde Özal'ın ölümünden sonra Çankaya'ya çıkan Süleyman Demirel'in cumhurbaşkanlığının ilk gününde bütün ülkeye yayınlanan ilk basın toplantısında yaşananlar gazetecilik refleksinin sona erdiğini gözler önüne serdi. Demirel konuşmasını yaptıktan sonra "Sorularınızı bekliyorum" dediğinde salonda ses çıkmadı. Demirel gazetecileri zorlama ihtiyacı hissetti ve "Korkmayın, korkmayın! Sorun" dedi. Tanınmış bir gazeteciye göre sessizlikle geçen o 30 saniye gazetecilikteki deformasyonun kanıtıydı. (TILIÇ, 1998)

1969 yılında Türk basınının amiral gazetelerinden Hürriyet'in yönetici kadrosuna katılan Nezih Demirkent (1930-2001), 13 Ocak 1980 tarihli köşe yazısında okurun beklentileriyle ilgili olarak şu yorumu yaptı: “... artık okur politize yayın organlarına fazla ilgi göstermemektedir. Fikir gazeteleri durumlarını zar zor korumaya çalışırken, magazin dergileri tiraj almakta, en ciddi gazeteler magazin ekleriyle yeni okurlara sahip olma yolunu seçmektedir. Çünkü okur, kötü haberlerden çok, iyi haberler veren yayın organlarının özlemi içindedir." Politize olan ve politik şiddetin yoğunlaştığı bir toplumda tatlı sözler duymak isteyen okurun magazin basınına ilgisini bir okur tepkisi olarak yorumlayan Demirkent başka bir olgunun varlığına işaret ediyordu. Basının endüstrileştiği 60'lı ve 70'li yıllarda, gazete sayfalarında magazin haberlerinin ve hatta magazin eklerinin artışı, halkın ilgisini çekecek siyaset dışı konulara ayrılması halkın apolitikleşmesinde basının oynadığı role dikkat çekiyordu. 70 'li yıllardan itibaren giderek büyük bir endüstriyel kompleks haline gelmeye başlayan basın, bu büyümeyle beraber sansasyonel ve magazinsel haberlere itibar etti. O döneme kadar gazeteler ciddi içerikleriyle tanınırken 1969 yılında yayınlanmaya başlayan Haftasonu ve 1982 yılında yayınlanmaya başlayan Bulvar gibi gazeteler magazin içerikleriyle farklı bir kulvarı oluşturuyordu. 1975 yılında bağımsız bir magazin gazetesi olarak yayın hayatına başlayan Kelebek, daha sonra Hürriyet gazetesinin eki olarak yayın hayatına devam etti. Hürriyet Gazetesi'nin her gün çıkartılan magazin içerikli eki oldu. Benzer şekilde Sabah Günaydın ekini, Milliyet ise Vitrin (2010 itibariyle Cadde) ekini çıkartarak magazini ikinci bir gazeteyle taçlandırdı. Bir yandan siyasilerle mesafeyi koruma bir yandan da tiraj artırma kaygısı el ele gelişti. Fiyatı ucuzlayan gazetelerde sayfalar dolusu magazin haberi otosansürün en yüzeysel hali olarak tezahür etti.

Magazine doğru yönelimi pekiştiren bir başka olgu ise televizyonun rekabeti oldu. Bu rekabete paralel olarak basın sektöründe baskı kalitesini artıracak yatırımlar artarken renkli sayfa kullanım uygulaması yaygınlaştı. Magazin sayfalarında popüler olmayan kişilerle ilgili haberlere yer verilmezken, popüler kişiler, gazeteyi satabilmek amacıyla ön plânda sunuldu. Popüler kültür, belirli malların yanında belirli düşünce ve dünya görüşlerini de popülerleştirdi. Popüler kültür ürünü olan gazete ve dergiler, ticari kültürün lehine, kapitalist topluma ve onun evrenselliğini getiren ideolojiye hizmet etmeye başladı. Ve yine benzer şekilde kadınlara yönelik magazin dergileri moda, kadın erkek ilişkisi, seks, evlilik, boşanma, doğum, güzellik, zayıflama, yemek tarifleri, dekorasyon gibi farklı konuları işlerken yine kapitalist topluma çıkarına yönelik içerik üretir oldu. Bu dergiler trend ve moda başlıkları altında ticari ürünlerin tanıtımını üstlenirken bireyleri tüketime yöneltti ve onlarda yeni ihtiyaçlar yarattı. Bu anlamda magazin dergileri tüketimi teşvik etmekte büyük rol üstlendi.

Magazin çok çeşitli haber konularıyla medyanın en güçlü silahı oldu. Sosyete dedikodusundan, sanatçıların yaşamına, sokak cinayetlerinden, hayat pahalılığına, çeşitli yemek tariflerinden, zayıflama metotlarına, yıldız fallarına kadar farklı alanlarda konular işlendi. Bu sayfalarda kültürel ve politik içerik bulmak mümkün değildi. Doğal olarak magazin haberciliğinin gelişmesi kültür haberlerinin gelişimini olumsuz etkiledi. Magazinin gölgesinde kalan kültür sanat sayfaları daima ilk gözden çıkarılan sayfalar oldu. illan gelmediğinde sayfa azaltmak gerektiğinde ya da tam tersi fazla ilan geldiğinde ve haberden kısmak gerektiğinde ilk atılan kültür sanat sayfalarıydı. Magazin haberlerinde haber atlamanın yöneticiler tarafından kabul görmediğini belirten halen ana akım bir gazetenin ekinde çalışan bir magazin muhabiri, "Gazeteler arasında magazin haberlerinde rekabet çok güçlü. Kültür sanat haberlerinde atlanan bir habere hiçbir ekin yöneticisi dikkat etmezken magazinde haber atlamak muhabir üzerinde yaptırım yaratıyor," diyor. Yapılan röportajların çoğunda oyuncu ve müzisyenlerden oluşan ünlülerin işlerini tanıttıklarını anlatan (ve adını vermek istemeyen) genç muhabir, "Röportaj yaparken kendimi ünlülerin yaptığı işlerin halkla ilişkiler (PR) çalışmalarını yapıyor gibi hissediyorum," diye konuşuyor.

Magazin haberleri kültür sanat haberlerini gölgede bırakırken kültür kavramı, tüketime entegre edilerek aslından uzaklaştırıldı ve bu kavramın içi boşaltıldı. Adorno'nun "kültür endüstrisi" olarak kavramlaştırdıkları olgu, insan yaşamına ve kültüre dair ne varsa tüketimin bir unsuru haline geldiğini iddia etmektedir. Tam da Adorno'nun üslubunu kullanan Hürriyet Gazetesi Genel Yayın Yönetmeni Çetin Emeç'in "Insan olan her şey magazindir" dediğini anlatan Atılay Kandemir "Her ne kadar sanatçılar üzerinden algılansa da magazin her şeyde vardır," diye konuştu. 1977 yılında Hürriyet gazetesinde 
çalışmaya başlayan ve uzun yıllar aynı gruptaki Haftasonu ve Hello dergilerinin yöneticiliğini üstlenen Kandemir "Çetin Emeç 'Insan olan her şey magazindir,' derdi. Parlamento muhabiri olabilirsin müsteşar, bakan... Spor muhabiri olabilirsin futbolcu, basketbolcu... Sağlık muhabiri olabilirsin doktoru, hemşiresiyle ilgili haber yaparsın. İnsan olan her şey magazindir. Onun için magazincinin her konuyla ilgili bilgisi olması lazım. Kültürlü olması lazımdır. Gözünün bir önde bir arkada olması lazım," diye konuştu.

Bu yorum bir yandan spordan istihbarata, siyasetten yurt habere, ekonomiden dış habere her departmanda işlenen haberin magazin boyutuyla sayfalarda yer bulduğuna işaret ediyor. Diğer yandan magazin habercisinin çok yönlü düşünebilmesi beklenirken basının hemen her bölümde tek boyutlu bir ürün ortaya koyduğunu gösteriyor. Nitekim kültür endüstrisi kuramı genel olarak kapitalist sistemin sahte ihtiyaçların hâkim olduğu bir dünya oluşturduğunu, bu dünyada yaşayanların ise tek boyutlu toplum olduğunu savunur. Adorno'ya göre, birey var olamıyor ve kapitalizm tarafından yönetilen dünya için şekillendirilmiş bir "toplumsal nesne" haline getiriliyor. Bu kuşatmayı dört bir yandan sağlayan magazin haberlerini hazırlayanların insana dair her konuyu işliyor. Tüketimde tek tipleşme konusunda rol modeli olmayı da 'seçkinler' üstleniyor. Bu konudaki en iyi örnek, Haftasonu ve Hello dergileri eski yayın yönetmeni, Milliyet magazin sorumlusu Atılay Kandemir'den geliyor. "Magazinin tüketimdeki rolüne bir örnek vermek gerekirse Arzu Sabancı yıllardır lüks segmentte, bir eteği 5000 Euro olan pahalı markalar giyer," diyen Atılay Kandemir, şöyle devam etti: "Arzu Sabancı geçen yıl Koton giyimle anlaştı ve onlar için tasarımlar hazırladı. Pantolon 80-90 lira, etek 40 liradan renkli kıyafetler yapıldı. Satışlar arttı. Bunun üzerine diğer firmalarda benzer çalışmalara gitti. Derin Mermerci Network Anadolu, Yasemin Özilhan İpekyol markası için tasarım yaptı. Gazeteye ilan verme gereği duymadılar çünkü magazin haberlerinde tanıtıldı. Yıllar evvel de Bisse'nin sahipleri Mustafa ve İbrahim Kefeli kardeşler, Sakıp Sabancı'ya bir gömleklerini giydirdi. Sako Sabancı "Ben yerli malı kullanırım," dedi. Bisse'nin satışları tavan yaptı. Ünlüler rol model alınıyor, örnek alınıyor. Batı'da da aynı şey yaşanıyor. Beckham bir saç tıraşı oluyor, herkes aynı yere gitmek istiyor. Bir şarkıı burnunu yaptırıyor, herkes aynısını istiyor. Her alanda benzer şeyler yaşanıyor, herkes ünlülerin peşinden gidiyor." Magazinin ön plana çıkardığı isimler 'seçkin' olarak kabul edilirken, tüketim alışkanlıklarıyla kitlelere rol model oluyor. Bu durum ünlüler ve üreticiler arasındaki ilişkileri güçlendirirken, bilinçli veya bilinçsizce etki altında kalan kitleler, manipüle edilen taraf oluyor.

Zira Atılay Kandemir'in verdiği örneklerde de görüldüğü gibi 'Kültür'ü 'endüstriyel' ölçekte üreten, tanıtan ve satan işletmeler doğası gereği kapitalisttir ve ürünlerini satma sürecinde kapitalizmi ve kapitalist ideolojiyi de satar. (WILLETTE, 2012) 19'ncu yüzyılın sonlarından itibaren 'kültür', muazzam bir kapitalist kâr sağlama aracı olarak biçimlendirilmiştir. Adorno'nun işaret ettiği totaliter bir Kültür Endüstrisi makro görünümünün yerini, magazin sayfaları veya internet siteleri gibi birçok mikro 'kültür' olgusu aldı (WILLETTE, 2012). Kültür endüstrisi, "vaat ettiğini yerine getirmeyen sahte tatminler dağıtarak", insanları kandırdı. Adorno'ya göre kültür, -tıpkı renkli basının yapmaya çalıştığı gibi- insanın kendine yaraşır bir toplumda yaşadığı sanısının uyanmasına yardımcı olarak, insanı rahatlatıp uyuşturmaktadır (ADORNO, 1998). Bunun sonucunda bireysel yaratıcılığın, özgün olmanın yerine büyük sermayeleri temsil eden ünlülerin taklidiyle tek tipleşen bir toplum ortaya çıkmaktadır.

Bu tek tipleşme moda ya da trendle yaratılan akımlarla yaratılan cazibesine kapılan kitlelerin rızasıyla oluşuyor. "Tüketimi magazin haberleri kadar körükleyen başka bir şey yok" diyen Haftasonu ve Hello dergisi eski yayın yönetmeni Erdem Kırım "Trend nedir?" diye soruyor ve şöyle devam ediyor. "Trend büyük bir kitlede gelişen bir davranış türüdür. Büyük bir kitle kısa bir sürede bir nesneyi, bir şeyi, hobiyi ya da bir insanı sevmeye başladığında bu bir trend olur. Bir çanta, bir motosiklet, bir araba hatta bir bardak kahve trend olabilir. Örneğin ünlü bir kahve zinciri markası derginin her sayısında bir ünlünün elinde kendi logolarının olduğu bir kahve bardağıyla fotoğrafının yayınlanmasını istedi, para konusunda anlaşılamadığı için yapılmadı. Muhtemelen başka bir dergiyle anlaştılar. Ünlü bir insanın günlük yaşamında yer alan her şey merak uyandırıyor. Aynı alışkanlık birden fazla ünlü tarafından edinilmişse trend oluşuyor." Nitekim trend herhangi bir mal veya hizmetin yükselme eğilimine işaret ederken, doğası gereği ekonomik bir ürün olma özelliğini taşıyor. Magazinin beslediği trendler ve tüketim kültürü arasındaki doğrudan ilişki, çoğu zaman haberde bir detay olarak süjesinin kullanım alışkanlığı, nadiren de haberin süjesi olarak ortaya çıkıyor. Magazinin alet edildiği bir diğer ürün tanıtım etkinliği ise davetler oluyor. "'Davet' adı altında sponsor firmaların reklamları yapılıyor" diyen Kırım "Ünlüler bu tarz ürünleri tanıtmak için aracı oluyor hatta bugün artık kendi sosyal medya sayfalarından tanıtımları ücret karşıı̆̆ı şahsen yapıyorlar," diye konuşuyor.

Milliyet gazetesi Cadde eki editörü Senem Aydın de "Ünlülerin cezbedici gücü markaları da baştan çıkarıyor," diyerek seçkinler ve markalar arasındaki ilişkiye vurgu yapıyor ve devam ediyor: "Örneğin Kıvanç Tatlıtuğ, satışlara olumlu etkisi nedeniyle birkaç sezondur Mavi markasıyla iş birliği yapıyor. Ünlü isimler giydikleri, yedikleri, içtikleriyle taklit ediliyor ve insanları tüketime özendiriyor. Günümüzde tüketim gereksinimleri ihtiyacın çok ötesine çıktığını hatırlatan Aydın şöyle devam ediyor: "Her alanda tüketim toplumunun hüküm sürdüğünü söyleyebiliriz. Özellikle magazinle birlikte insanlar tüketime teşvik ediliyor. Ünlü isimler kullanılarak özendirme yapılıyor. Moda, spor, sanat birçok alanda magazini işin içine katarak insanlar belli ürünleri almaya, belli mekanlara gitmeye yönlendiriliyor. İhtiyaçlarının dışına çıkarak tüketime davet ediliyor." Türkiye'de dergi ve gazetelerin magazin sayfalarını incelediğimizde gerçekten de tüketime yönelik yaşam tarzlarının başat gittiğini ve tüketim kültürüne ilişkin içeriklerin çoğunlukta olduğunu görmek mümkün. 


\section{BULGULAR VE TARTIŞMA}

Türkiye'de Batı tüketim kalıplarının yerleşmeye başlamasında magazin haberleri lokomotif bir rol üstlendi. Doksanlı yıllar, basın sektöründe yaşanan tekelleşmenin ve gazeteci-patronun yerini iş adamına bırakmasıyla başlayan süreçte magazinin yükselişine sahne oldu. 1980'li yıllar itibariyle sahiplik yapısının el değiştirmesiyle kültür ürünü olan basın kapitalizmin aracı haline gelirken, yeni medya magazini kullanarak toplumsal bir dönüşümü başlattı. Sahiplik yapısının değişmesiyle aynı dönemde gelişen burjuva sınıfı seçkinler olarak lanse edilirken, magazin süjeleri olarak toplumsal dönüşümde rol model olmuş, kendini besleyen bir sistem yaratıldı.

Gazetelerin sahip değiştirmelerinin özünde iş adamlarının kar etme hedefi kadar saygınlık ve prestij kazanma arayışları da yer alıyordu. 80'li yıllar itibariyle büyük sermayenin giderek daha fazla etkisi ve denetimi altına giren yayın organları, TV ve radyo bu ideolojik tavrın yerleşmesinde kilit rol oynadı (BORATAV, 2007). Aynı dönemde 1980 öncesinin kamuoyu karşısına çıkmaktan çekinen, bir anlamda görünmez olan burjuvazi, medya aracılığıyla görünür olmaya başladı. Geçmişin 'sömürücü, kapitalist, patron' imajı yerine 'saygınlık' kazandırılmaya çalışan burjuva imajına geçişte, ana akım medya büyük rol oynadı.

Medya eliti-yeni seçkin-orta sınıf', burjuvazinin gelişmesi ve güçlenmesinde adına üstlenildiğini ana akım medya destekli bir yol izledi. Geniş toplum kesiminin sınıf atlama hayalini canlı tutan bu tarz haberler aynı zamanda burjuva-üst sınıf-elitlerin 'kalkınma, modernleşme, çağdaşlaşma, ilerleme' gibi idealler için vazgeçilmez görünmelerini sağlıyordu. Tarihsel koşullar nedeniyle üst sınıfın 'burjuvazi' olarak sınıflandırılması 'kültürel alana' nüfuz etmemiş olduğu için burjuva sınıfının siyasal alana yaptırımını kısıtlayan koşullara karşı, bu sınıfın meşruluğunu sağlama görevi aydınlara düşüyordu. Burjuvaların ve elitlerin çıkarlarının toplumun çıkarları gibi gösterilmesi medya elitleri aracılı̆ı̆la burjuvazinin Gramsci'nin deyimiyle 'organik aydınlar'ının görevi oldu. Var olan sistemin propagandasını yapan, doğruluğunu kabul eden ve bir şekilde egemen sınıfın, ideolojisinin yayılımını sağlayan bu aydınlar, 'egemen sınıfın toplumsal hegemonya ve siyasal idare işlevlerini yürüten 'vekilleri' veya üst yapı memurları' oldu (CREHAN, 2006). Söz konusu aydınların bağlı oldukları sınıfın kültürel hegemonyası için düşünsel araçlar geliştirme, ideolojik işlevler üstlenme gibi rolleri oluştu. Burjuva ve elitlerin çıkarlarının toplumun çıkarları olarak gösterilmesi de yine organik aydınlarının işlevleri arasında yer aldı. Bütün bu gelişmelere paralel olarak medya elitleri, toplumun en etkili ve en güçlü kesimlerinden biri haline dönüştü (ASTIZ, 1969). Medya kuruluşlarının yöneticilerinden, editörlerinden, etkili köşe yazarlarından ve raportörlerde oluşan medya elitleri sınıflar arası ve sınıf içi rekabet koşullarında ise medya elitleri 'güçlülerin silahı' olarak ortaya çıktı.

Kitleleri tüketime teşvik eden magazinin en önemli rolü 'burjuva, üst sınıf, elit' olmayı özendirmek oldu. Türkiye toplumunun artan hızla tüketim toplumuna dönüştüğü bu dönemde, medyanın tüketim kültürünü tanıtması ve sunması, medya sahiplik yapısının sermaye grupları tarafından tekel altına alınması, yeni bir dönemi simgeliyordu (ÖZŞEKER, 2013).

Ülke nüfusunun yüzde 60'nın 25 yaş altında olduğu bu dönemde magazin haberlerinin okuru baştan çıkarıcı davetiyle mekân ve yemek çeşitlerinin tanıtıldı̆ı gusto-stil köşeleri, sınıf ve statü belirten ürünlerin basın bültenlerinin kullanılması, gurme, lifestyle, trend gibi kavramlarla yapılan tanıtımlar yeni yaşam alışkanlıkları empoze edilir oldu. 1980'li yılların sonuna gelindiğinde artık kitle gazeteciliği anlayışı ön plana çıkarken basın kuruluşları okur değil 'tüketici' odaklı çalışıyordu. Gazetelerde haber merkezlerinin yanı sıra reklam ve pazarlama departmanları da önemli ölçüde yönetimde ağırlıklarını hissettirir hale geldi (ÖZGEN, 2008). Zafer Mutlu'nun deyimiyle yükselen yeni nesiller beraberinde yeni değerler taşıdı (BALI, 2007). Yükselen yeni değerler; lüks lokantada yemek, kaliteli giyinmek, lüks araba sahibi olmak, yurtdışına seyahate gitmek gibi bir zamanlar çok varlıklı kesimin tekelinde olan ama 80'li yıllar itibariyle orta sınıfın da erişmeye çalıştığı bir yaşam tarzını özetleyen bir kavramdı (BALi, 2007).

İşte köşe yazarlarının ana misyonu da yükselen bu yeni değerleri tanıtmak, yaygınlaştırmak ve hatta öncülüğünü yapmak oldu. Ekonomi yazarı Ege Cansen'in deyimiyle "konusu kendisi haline gelen" (CANSEN, 1998) bu yazı tarzında cinsel yaşamdan aşk hayatına, evde beslenilen evcil hayvanlardan modaya, en son gidilen restoranlardan yapılan diyetlere, sosyal ve kültürel etkinliklere, en son okunan kitaba kadar çeşitli konular yazılıyordu. Yazılarını birinci tekil şahıs olarak kaleme alan bu yeni nesil köşe yazarlarının yanı sıra ciddi köşe yazarları magazin yazarak gündeme geldi, kendi alanları dışında, magazin içerikli yazılar kaleme alır oldu. Bu noktada, karşımıza çıkan magazinleşme olgusu konformist bir hayat tarzına ve tüketime yönlendirirken tüketimi artırmış şov haline getirmiş, bu şov ruhuyla dayanışma ve yardımlaşma duygularını zayıflatmaya başlamıştır. Magazin gazeteciliğinin temel özelliği insanların hoşça vakit geçirmesini sağlayacak genellikle ciddi meselelerden uzak içerik taşımasıdır. Magazin haberlerinin amacı okuru eğlendirmek ve düş dünyasına götürerek duyulara hitap etmektir.

Sanatta, özellikle de müzikte, reklamın ve bunun sonucu olarak dayatmanın önemini vurgulayan Adorno'ya göre genel olarak düşünüldüğünde, izleyici, reklamı yapılan maddenin üstün gücüne teslim olmakta, dayatılan malları kendine ait kılarak "ruhsal huzur satın almaya” çalışmaktadır. Adorno'nun bu değerlendirmesi magazin haberleri açısından da geçerlidir. Burada "ruhsal huzur satın alma", "kişisel zevk" olarak tanımlanmakta ve kişinin, kendisine yutturulan şeyle özdeşleşmesi sonucu oluşan "pasif bağımlılık"ın reddedildiğini belirtmektedir. İşte bu kişi, "en rahat ve akıcı" ve tekrarla hazırlanan "bir çocuk besini"ni tercih etmekte, aşina olmadığı her şeyi ise kibirli ve cahil bir tutumla reddetmektedir. Yeni tüketim alışkanlıklarını tanıtan magazin haberleri 'kolay hazmedilen bir mutfak nesnesi' halinde servis edilir hale getirilmiştir. 
Okuyucuyu bilgilendirmekten çok, ona eğlenceli zaman geçirtmek amacıyla yapılan magazin haberciliğinin bu kadar tutulmasında sadece haberi yapanlar değil, onu okuyanlar da sorumludur. Örneğin Hürriyet gazetesinin internet sitesinin yöneticiliğini üstlendiğinde magazin haberlerini azaltmayı hedefleyen Fatih Çekirge ise bu konuda başarılı olamamıştır. Kırım'ın belirttiğine göre ciddi tıklama oranı düşüşlerinin yarattığı yaptırımla magazin haberleri hurriyet.com.tr adresinin yine en sık rastlanan ve okunan haberleri olarak yerini korumuştur.

\section{SONUÇ}

Adorno kültür endüstrisinin liberal endüstri toplumlarından çıkmasını olağan olarak değerlendirmiştir. Bunun nedeni liberal endüstri ülkelerine özgü medyanın ve özellikle sinema, radyo, magazin basını ve caz müziğinin zaferlerini bu ülkelerde ilan etmiş olmasıdır. Medyanın bu kadar güçlenmesinin en önemli nedeni ise sermayenin belirli bir yapı içinde değerlendirilmesi ve bu sermaye yapılanmasındaki temel amacın kâr elde etmek olmasıdır. (KOLUAÇIK, 2017) Nitekim bugünün medyasının ürünlerine genel olarak bakıldığında tüketimi arttırıcı ve yeni tüketici kimliklerin oluşmasına yol açan bir eğilim taşıdığı dikkat çekmektedir. Özellikle medya içeriklerinde okurun arzularına seslenen magazinleşmiş bir söylemin hâkim olduğu görülmektedir (PAKLACI, 2014). Topluma sonu gelmeyen gösteri sunumunda bulunan magazin haberleri, kolektif zihinde olgu ve olayların nedensellik ilişkilerinden kopmasına yol açmaktadır. DESAM'ın araştırmasına göre bu durumda sisteme yönelik sorgulamaların üretilmesi olanaksızlaşırken toplum kendi değerlerine yabancılaşmaktadır. Eleştirellikten uzak ve apolitik bir toplum üreten kültür endüstrisinde toplumsal sistem, adeta eleştirel bir akla sahip ve nitelikli içerik beklentisinde olabilecek bir toplumun oluşmasının engellenmesini hedeflemektedir. Siyasal, sosyal, ekonomik ve kültürel dinamikler toplumu eğlenceye iterken eleştirellikten uzaklaştırmaktadır (KARAHAN, 2002). Demokrat Eğitimciler Sendikası Araştırma Merkezi'nin (DESAM), 2011 yılında 'Internet ve Televizyon Kitap Okumayı Engelliyor' konulu araştırmasına göre otosansür yöntemi olarak kullanılan ve dayatılan magazin haberleri, kitap okuma oranının düşmesiyle beraber okurun talep ettiği ve tercih ettiği bir mecra olmuştur.

Kültür endüstrisinin Türkiye'deki gelişimine paralel olarak iç dinamikler de darbelerle uygun zemini hazırlamıştır. 12 Eylül 1980 öncesi ülkede her şeyin aşırı politize olmasına karşın, bu tarihten sonra toplum adeta hafızasından arındırılmak suretiyle apolitik bir mecraya taşınmak istenmiş ve bugünkü sonuçlar dikkate alındığında bu, başarılmıştır ve gelinen noktada toplumun apolitize edilmesinde medya önemli rol üstlenmiştir. (ÖZGEN, 2008).

Basın mensuplarının basın tarihinin ilk yıllardan itibaren sürgün ve suikastlarla susturulmasının ve darbelerin ardından kültür endüstrisiyle değişen gazetecilik anlayışında sansürün yerine bugün otosansür refleks halini almıştır. Yayın yönetmenlerine 'itaat' eden bölüm şefleri, bölüm şeflerine 'itaat' eden genç muhabirler ilişkiler ağı içinde fikirlerini kendine saklamayı öğrenmiş, "Ama" diye başlayan cümlelerin bile yasak olduğu haber merkezlerinde basın özgürlüğü sadece hedef olarak kalmıştır. Bu süreçte medya içeriklerindeki magazinleşme sonucunda toplumda merak uyandıran, hoşça vakit geçirtici konular yoğunluk kazanmış ve siyasi, sosyal, ekonomik nitelikli konular eğlendirici hale getirilerek ve bağlamlarından koparılarak sunulmuştur. Gardel'in (GARDELS, 1998) deyimiyle dördüncü güç, 'bilgilendirici güç' olmaktan çıkıp 'eğlendirici güç' haline gelmiştir.

Pek çok araştırma magazin sayfalarında dikkat çeken başlıca sektörlerin; yemek ve eğlence mekanları, gösteri, konser, sergi gibi kültür etkinlikleri, moda, sağlık ve spor olduğunu ve bu alanlarda tüketim kültürünü beslediğini ortaya koymuştur. Oysa ortaya koymuş olduğumuz üzere sektör sınırlaması olmadan eğlenceli vakit geçirmeye hizmet eden her şey, kültür endüstrisinin tüm unsurları magazin haberlerinde yer bulmuştur. Tüketim toplumuna dönüşen Türkiye'nin tüketimi körükleyen bir medyadan nemalanmaya devam etmesi kaçınılmaz görünmektedir. Kültür endüstrisinin getirdiği asıl yenilik, kültürün uzlaşmaz iki öğesini sanatla eğlenceyi amaç kavramına yani tek bir yanlış formüle, kültür endüstrisinin bütünselliğine tabi kılmış olmasıdır. Var oluş amacını eğlendirmek olarak özetleyebileceğimiz magazin haberleri, holdingleşme sürecinde el değiştiren Türk basınında ise güçlü sermayeleri olan yeni sahipleriyle beraber, habercilerini de seçkinlerin dünyasına sokmuştur. Pareto'nun seçkinler dolaşımı olarak tanımladığı, bir elit grubun yerini başka bir elit grubun alışı gerçekleşmiş, Türkiye tarihindeki en büyük dönüşümlerden biri yaşanmıştır. Bu döngü günümüzde yeniden el değiştirmeyle tekrar ederken belirli bir eğitim sermayesine sahip olan medya profesyonelleri belirli bir yaşam tarzının hâkim olduğu toplumsal ilişkiler şebekesine girmiştir. Bu son dönüşümle birlikte resmi rakamlara pek yansımamakla birlikte gazete tirajlarının günden güne düşüyor olması, mevcut yazılı basının değişim ihtiyacına işaret etmektedir. Sözcü gazetesinin 1 Mart 2018 tarihli 'Toplam 3 milyon gazetenin yarısı bedava dağıtılıyor' başlıklı haberine göre düşük satış rakamlarını gizleyen gazeteler, hileli yöntemlerle tirajlarını yüksek göstermekte, yaklaşık 3 milyon gazetenin yarısı hastane, site, büfe ve marketlerde bedava dağııılmaktadır. Düşük tirajlı gazeteler sadece 4 sayfalık kapağı basıp 130 bin tiraj gösteriyor. Mamafih başkalarının hayatlarına tanıklık edilen magazin haberlerinin reytinglerdeki başarısının yerini aynı reklam tekniklerini kullanarak tüketimi körükleyen dizi sektörü almıştır.

Adorno'nun dikkat çektiği önemli bir nokta kültür endüstrisinin eğlence kurumuyla iç içe geçmiş olmasıdır. Eleştirel teorisyenlerin kültür endüstrisi ürünü olarak tanımladığı sinema, televizyon, radyo, popüler müzik, gazeteler, magazin dergileri gibi eğlence endüstrisinin de ürünleri acıları unutturarak insanları pasifleştirmiştir. Sorgulamak ve hatta düşünmekten yoksun kitleler birbirine benzemeye başlar. Birbirine benzemek de teskin edici başka bir Adorno, kültür 
endüstrisini tanımlarken şu iddiaya başvurur: Teknolojik gelişim ve farklılaşma, toplumsal ve sınıfsal değişimler kültür alanında da bir farklılaşmaya yol açmaz, aksine kapitalist sistem kültürleri de bütünleştirir ve birleştirir. Kültür her şeye benzerlik bulaştırarak ortalama ve popüler bir anlayışı ortaya çıkarır (ADORNO, 2011). Kültür endüstrisinin ideolojisi öyle güçlüdür ki bilincin yerini uygitsincilik alır (ADORNO, 2003). Magazin haberlerinin izleyicisini dizilere kaptırmasının arkasında yatan da bu ruh halidir. Adorno, politika ve ekonomi aracılığıyla kültürün yönlendirilmesine şiddetle karşı çıkmakta ve "halka yakın", popülist ve "halk kültürü" olarak ifade edilen her türlü sanatı küçümsemektedir (LUNN, 1995). Ancak Adorno aynı eleştirileri 'kültür tüketicisi'ne de yöneltmektedir. Günümüzde de geçerliliğini koruyan bu eleştiriler, 'kültür tüketicisi'nin değerlendirme yönünden yetersizliğini çok iyi betimlemektedir (KAYIKÇI, 2013). Buna göre "kültür tüketicisi", "kendini feda etmeyi seven", "moda olanı izleyen" ve bu nedenle, dün kendinden geçercesine bağlandığı şeye, o zaman kendinden geçerek bağlandığı için öfke duyan, bu şekilde kendinden öç alan davranış özelliğine sahiptir. Bu davranış özelliği de "kültür tüketicisi"nin sadomazoşistik yönünü ortaya koymaktadır. Kültür endüstrisinin her gün yenilediği ürün politikası ile günden güne daha mutsuzlaşmak ve yalnızlaşmak yerine kendi sorumluluğunu alarak uyanış içine girmek tüketicinin her an tercih edebileceği bir seçenektir.

\section{KAYNAKLAR}

Abasıyanık, S. F. (1965). Son Kuşlar-Mahkeme Kapısı. İstanbul: Varlık Yayınları.

Adaklı, G. (2006). Türkiye'de medya endüstrisi. Ütopya Yayınları, Ankara.

Adorno, T. (2003). Kültür endüstrisini yeniden düşünürken. Cogito, Sayı: 36.

Adorno, T. (2011). Kültür endüstrisi-kültür yönetimi. (Çev. Elçin Gen, Nihat Ülner, Mustafa Tüzel), İstanbul: İletişim

Adorno, T. (1998). Minima Moralia. Metis Yayınları, İstanbul.

Akbal, O. (1992). 12 Mart yanılgısı, Babıali'de 50 yıl. (Yazı Dizisi-9), Milliyet, 15 Nisan.

Akün, Ö. F. (2002). Ahmet Hamdi Tanpınar. Bir Gül Bu Karanlıklarda -Tanpınar Üzerine Yazılar-, İstanbul Kitabevi.

Balı, R. (2002). Tarz-ı hayat'tan life style'a. İletişim Yayınları, Istanbul.

Bali, R. (1999). Yeni aristokratlar: köşe yazarları. Birikim, 117/Ocak.

Baysal, F. (2003). Gün ışığı Sait Faik Abasıyanık. Hazırlayan: Sevengül Sönmez, Kitaplık, 57.

Bottomore, T. (1990). Seçkinler ve toplum. Gündoğan Yayınları.

Çıkla, S. (2008). Son araştırmalar ışı̆̆ında Yahya Kemal'in şiirlerinin kronolojik bibliyografyası. Yahya Kemal Beyatlı, Editör: Kâzım Yetiş, İstanbul: Kültür Ve Turizm Bakanlığı Yayınları.

Çıkla, S. (2009). Tanzimat'tan günümüze gazete-edebiyat ilişkisi. Türkbilig.

Gardels, N. (1998). From containtment to entertaintment. New Perspectives Qaterly, 15(5): 2-5

Gülendam, R. (2004). Demokrat Parti iktidarında edebiyat-politika/siyaset ilişkisi ve edebiyatçılarımızın bu süreçteki yeri. Hece (HayatEdebiyat-Siyaset Özel Sayısı), 90-9192.

Gür, A. (1983). Sermaye yapısında değişim ve dergiler. Cumhuriyet Dönemi Türkiye Ansiklopedisi, Cilt 11, İstanbul: İletişim Yayınları, S.146.

Hallın, D. (2005). Eleştirel kuram perspektifinden Amerikan haber medyası. Ütopya Yayınevi.

Karahan, U. Z. (2002). yazılı ve görsel medyada magazinleşmenin tarihsel ve sosyolojik dinamikleri. İletişim Dergisi, Ankara Gazi Ü. Basımevi, Sayı :12, Kış.

Kayıkçı, M. (2013). Adorno'nun kültür endüstrisi kavramı üzerine. Afyon Kocatepe Üniversitesi, Blog.Aku.Edu.Tr/.

Koluaçık, İ. (2017). Eleştirel teorisyenlerin kültür endüstrisi kavramı çerçevesinde sanata ve sinemaya yaklaşımları. Abant Kültürel Araştırmalar Dergisi (AKAR), 2017, Cilt 2, Sayı 3, 135-156.

Kılıç, A. (2015). Gazeteci, aklına koyduğunun peşinden gitmeli. Gazete Kadıköy, İstanbul.

Koloğlu, O. (2013). Osmanlı'dan 21. yüzyıla basın tarihi. Pozitif Yayınları, İstanbul.

Lunn, E. (1995). Marksizm ve modernizm. Alan Yayınları, İstanbul.

Sayer, A. (1998). Critical and uncritical cultural turns. Lancester Üniversitesi, Sosyoloji Bölümü.

Özgen, M. (2008). 1980 sonrası Türk medyasında gelişmeler ve magazinleşme olgusu. Siyasal ỉletişim Enstitüsü.

Özkök, E. (1982). Sanat iletişim ve iktidar. 1.Basım, Tan Yayınları, Ankara, S.189-190.

Paklacı, B. (2014). Dünya'da kültür endüstrisinin Adorno sonrası değerlendirilmesi. Trakya Üniversitesi Görsel Kültür Anabilim Dalı. 
Tilıç, D. (1998). Utanıyorum ama gazeteciyim Türkiye ve Yunanistan'da gazetecilik. İletişim Yayınları, i̇stanbul.

Weber, M. (1968). The theory of social and economic organization. New York, The Free Press.

Willette, J. (2012). Theodor W. Adorno ve kültür endüstrisi üzerine. (Theodor W. Adorno And The Culture Industry), Www. Heathwoodpress.Com. 